\title{
INDUMENTARIA MORISCA VALENCIANA
}

\author{
Por \\ CARMEN BARCELÓ y ANA LABARTA
}

En 1526, los doce síndicos representantes de las aljamas musulmanas del reino de Valencia pactan con el rey que "por quanto los dichos moros tienen bestidos moriscos los quales son differentes de los bestidos cristianos señaladamente lo de las mugeres, a las quales sería muy grave averlo de mudar y se perderían porque ningún provecho se podría sacar dellos, suplican por ende que por espacio de (...) quarenta años no puedan ser forzados de mudar dichos bestidos" (Boronat I, 4241 .

Hasta el presente apenas se ha dedicado atención al aspecto que tenía la población morisca valenciana en lo que se refiere a su indumentaria, atavios y joyas (1). Las notas que siguen sólo pretenden ser una primera aproximación al tema, para poder abordar, en su día, un estudio más amplio sobre trajes, colores, gustos, etcétera.

Un testimonio interesante sobre el "ambiente" morisco, desde el punto de vista que aquí interesa, lo constituye la descripción que hizo B. Joly (1603-4) durante su visita a Gandia: "Después de la comida, el señor del Cister quiso que aquellas gentes viniesen a bailar a la morisca, al son de una gran guitarra como un laúd que uno de ellos tocaba sin distinción de sonidos; después aparecieron tres o cuatro bailarines moros y seis mujeres, más modestas que bellas, vestidas con trajes de tela trabajada de seda, con grandes $y$ anchas mangas abiertas por los costados, de seda de color, un pequeño sombrero sobre la cabeza, zapatos rayados en los pies y (...) tenian también sortijas de oro y plata, brazaletes y collares en los dedos y en los brazos, en el cuello, y en las orejas, pendientes monstruosamente grandes" (García Mercadal, 1959, II, 78). Algunas de las piezas señaladas por el visitante francés aparecen descritas en inventarios $y$ documentos cristianos; otras se mencionan en los textos árabes de los moriscos (cartas dotales, cuentas, relaciones, etc.) que se han conservado hasta hoy.

(1) Sobre el traje y los elementos de la indumentaria valenciana en los siglos XVIII y XIX han aparecido recientemente tres artículos de interes: $V$. FERRANDIS I MAS, «Elementos para el estudio de la indumentaria valenciana: vestido de la mujer (1787-1812) (l)", Torrens (Estudis i Investigacions de Torrent i comarca), 1, 1982, 65 . 128. Y "Elementos para ef estudio de la indumentaria valenciana: el vestido del hombre $(1787-1840)$ y $(1 /) *$, To rens $2,1983,115-161$; F ZANON RODRIGO, "Las joyas: una aportación a la indumentaria valenciana 1 1801-1809m. Torrens, 1, 1982, 129-176. Hay algunas referencias a joyas también en el articulo de J. MAlSO y R. BLASCO, "Dos señorios alicantinos con vasallos moriscos a través de los registros notarialesw, Les morisques et leur temos, Parfs, 1983, 335-354 (ct. pág. 350). 
Partiendo del despoje de procesos inquisitoriales, inventarios de bienes requisados y noticias sueltas en documentación cristiana, se ha procedido a una recogida de datos sobre indumentaria, que se han ordenado alfabéticamente $y$ constituyen la primera parte de este trabajo. De forma similar se ha procedido con los textos árabes, unos ya editados y estudiados por quienes esto escriben, $y$ otros inéditos (como los que se incluyen en apéndice) cuyas referencias, también ordenadas alfabéticamente, forman el segundo apartado. Cada voz se ha completado con las noticias que han parecido de interés, sin pretender agotar el tema.

Hay que señalar, por otra parte, que el propósito de este trabajo es tan sólo el de recoger e identificar los términos atestiguados, sin entrar en pormenores respecto al valor testimonial de las fuentes. Un estudio ulterior, destinado a analizar la evolución de la indumentaria morisca, tendrá naturalmente en cuenta el que las prendas se mencionen en acidaques o inventarios de bienes - con lo cual podría tratarse de ropas en desuso- o conste en la documentación que se vestían en determinada fecha.

Sin desdeñar los numerosos trabajos que se han ocupado de la indumentaria morisca granadina, ha parecido conveniente no tenerlos aqui en cuenta, pues, mientras no se conozca mejor el "mundo morisco valenciano", es difícil poder establecer convergencias, similitudes o discrepacias entre ambas.

\section{Trajes y complementos atestiguados en documentación cristiana}

alfilel. Documentado en 1499 entre las mudéjares de Manises (Barceló. $1980,60)$. Debe tratarse del velo llamado alfirem o alfilem en otras fuentes y conocido en textos castellanos como alhareme (Bernis, 1979, II, s. $v$. "alharemes").

aljuba. En 1351 se menciona una aaljuba de cotó" entre los bienes de un mudéjar de Alfarb. (Cf. Bernis, 1979, II, s.v.) Véase también "gipó o jubón".

almaizar. Toca consistente en una banda de tela de varias varas de largo que se llevaba enrollada a la cabeza como un turbante. Bernis $(1979,11,57)$ supone que esta prenda era de telas de colores - generalmente sedas - a diferencia del alhareme, que se hacía con telas de lino (blancas o amarillentas), pero en un inventario de 1602 se menciona «un almaysar blancon, aunque sin especificar el tejido (AHN, Inq., leg. 554/18).

alpargata. 1585 "una sarria de alpargates" (AHN, Inq., leg. 552/37). Véase infra $\$ 2 . b, s . v$. "bargat".

alquinal. Velo o toca femenino. Se menciona como traje típico de las mudéjares de Manises, que cubrían su rostro con este tocado (Barceló, 1980, 60). Véase infra $\$ 2 . b$, s. v. "kina ${ }^{\mathrm{c}}$ ".

arrehuelo (?). 1585 «arrehuelo negre ab una girada de vellut» (Barceló, $1984,107\}$.

barret. 1513 "un camelot ab barret de bellut" (ARV, Bailia 329, f. 631).

basquinya. Esta prenda de mujer para vestir a cuerpo aparece en los inventarios como un traje de lujo. Según Bernis (1979, II, 133-4) estas faldas 
solian guarnecerse con "tiras" de otra tela y color, que se colocaban en el ruedo. Las vestían las niñas moriscas (AHN, Inq., leg. 549/22) y se dice que unas eran "de girasol" y otras de "drap vert" cosidas con "fil y seda" (1591. ARV, Clero, leg. 749/1949-50). Las más ricas, citadas en un acidaque, eran "de seda, guarnides de vellut", que hacía juego con las mangas, también de terciopelo (1604. APN, Prot. F. Sanchis), o wa la cristiana, de tafetán girasol de grana y amarillo, con guarnición de terciopelo negron (1563. Véase Apéndice, C). Las corrientes solían ser de paño, a veces con adorno del mismo color, como una morada "con faxas moradas" (1602. AHN, Inq., leg. 554/18). Los colores citados son el azul, verde, colorado, amarillo y morado 11602 . AHN, Inq., leg. $554 / 181$.

borcegul. Este tipo de calzado masculino se menciona en 1446 entre los bienes embargados a un zapatero y se especifica que son "borceguins marroquins" (Barceló, 1980, 61).

bossa. Era un complemento tanto masculino como femenino. Las que usaban los hombres eran de lienzo y podían tener en su interior "un bolsico" 11585, 1590, 1599. AHN, Inq., legs. 552/37, 554/6, libro 938, f. $52-54$ ). Entre las de mujer se mencionan "con una telilla" o "de telilla blanca y verde, con un cayrelico de oron (1602. AHN, Inq., leg. $555 / 21$ ), o de urazo colorada" (1606. AHN, Inq. leg. 549/13). La más lujosa pertenecía a una mudéjar de Valencia y se describe en 1513 del modo siguiente: "una boça de broquat migancera, de dona, ab un estoig daurat usat" (ARV, Bailia 329, f. 631).

brial. Esta era una prenda para vestir a cuerpo y sólo se menciona una vez, en un texto procedente de la Valldigna de 1585. Debía ser una falda para ocasiones solemnes y sólo al alcance de las moriscas más ricas, como la dueña de este vestido, esposa de un mercader. Se dice del brial que era "vergat de cotonina, usat» (Barceló, 1984, 107). Véase infra § 2.b, s. v. uibriyaln.

calzas. Sólo se menciona esta prenda femenina interior en fecha tardía (1602). Según cierto testigo, una mujer se ató ula atapiernan para ocultar "en la calçan algo que luego le fue hallado "entre la carne y la calça" (AHN, Inq., leg. 554/21 y libro 938, f. 1691. Aunque no se indica de qué tejido estaban hechas, la costumbre morisca era utilizar el lino. (Cf. Bernis, 1979, II). Véase infra § 2.b, s. v. "kalsa».

camisa. Era una prenda interior, tanto de hombre como de mujer o de niño. Las de las mujeres podian no tener mangas: "camisa morisca sin mangas" (1602. AHN, Inq., leg. 554/18) "camisa nova, sense cabes ni punyets" (1585. Barceló, 1984, 107). Se ponía junto a la carne y se cubría con el sayo o saya 11575. AHN, Inq., leg. 554/4; 1602. AHN, Inq., leg. $555 / 211$. Las había de seda de colores, listadas y bordadas: "camises llistades» (1497. Barceló, 1984, 106), "camisa obrada de seda negra, de dona", "camisa de dona obrada de seda de grana" (1585. Barceló. 1984, 107), "camisa limpia labrada de grana» (1599. AHN, Inq., libro $938, f .77)$. En los procesos inquisitoriales se hace referencia a menudo, y como costumbre morisca, a la muda de camisa para hacer la oración islámica. 
capa. Era una prenda usada por hombres y mujeres y no aparece ninguna distinción en los textos consultados. De unos moriscos se dice que "dormían embueltos con sus capas" (1602. AHN, Inq., leg. 550/11). A lo que parece eran de colores oscuros: "una capa negra usada molt", "una capeta parda vellan (1585. Barceló, 1984, 107). Algunas llevaban una especie de capucha: "la capilla de la capa» 11600. AHN, Inq., libro 918, f. 206). Véase infra § 2.b, s. v. "kabâ".

çaragüelles. Vide "saraüell».

cosset. Debe tratarse de la prenda femenina que $C$. Bernis describe bajo la voz cos (1979, II, 80-81). Según esta historiadora, el cos era una especie de corpiño interior que podía llevar o no mangas. Sólo se documenta en dos ocasiones: "cosset d'estamenya scarlat" (1513. ARV, Bailia 329, f. 6311, "cosset de vellut negre, ab ses mànegues ab randes de or" (1585. Barceló, 1984, 107). Debe ser lo que se menciona como cueroo en 1563: "un cuerpo de rasso carmessí con sus mangas» (Cf. Apéndice. C). También debe corresponder al mismo tipo de vestimenta «un corpiño de paño negro" (1607. AHN, Inq., leg. 935, caja 2 ).

cota. Según Bernis, la cota era una prenda femenina parecida al hábito, mongil o faldilla y, por tanto, un vestido exterior. Los textos en que aparece este traje sólo mencionan la "mija cotan por lo que se puede deducir que no llegaba hasta el suelo; una de ellas iba acompañada de una faja: "mija cota teuada usada", "mija cota de tafatà negre, ab una faxa de vellut negre" (1585. Barceló, 1984, 107). Véase infra § 2.b, s. v "q.t.».

davantal. Usaban el delantal tanto las mujeres como los hombres artesanos; en 1446 se cita "un devantal rexat" de un zapatero (Barceló, 1980, 61). En una ocasión se dice que es de "fil, ab llistes grogues" (1513. ARV, Bailia 329, f. 631). También se cita "un debantal de lana listado" (1607. AHN, Inq., leg. 935/2). A través de los procesos inquisitoriales puede observarse como las moriscas eran sorprendidas en sus casas con "devantaln 11602. AHN, Inq., leg. 554/19; 1604. AHN, Inq., libro 938, f. 2631 .

esparteñas. Este calzado, conocido también como alborga, era muy parecido a la alpargata. Se cita a un morisco que las vendia (1577. AHN, Inq., leg. 551/311. Era un zapato de labradores hecho de esparto o cáñamo; "unas esparteñas de cáñamo" se citan entre las ropas de casa de una viuda morisca 11607. AHN, Inq., leg. 935, caja 2).

faixa. Además de un complemento de otras prendas (ver cota), esta banda de tela era un accesorio que hombres y mujeres se ponían alrededor de la cintura sobre el vestido exterior. En 1584 se menciona "la faxa" de una mujer (AHN, Inq., libro 936, f. 375) y en 1599 se dice de un morisco que llevaba "una faxa que traya çeñida" (AHN, Inq., libro 938, f. 54).

falda. Esta parte de la prenda de vestir femenina que cae desde la cintura se menciona con cierta frecuencia en los procesos inquisitoriales por ser el primer sitio en que las moriscas ocultaban papeles u otros objetos que no querían que les fueran descubiertos. Asi: "entre las faldas" (1603. AHN, inq., leg. 551/6; 1602. AHN, Inq., leg. 554/19), "baxo las faldas" (1604. AHN, Inq., libro 938, f. 241), "debaxo las faldas" o "debaxo de 
sus faldasn 11604 y 1609 . AHN, Inq., libro 938, f. 355 y libro $939, \mathrm{f}$. 13), "traya la falda arremangada" (1583. AHN, Inq. leg. 550/6). Ya fray Hernando de Talavera en 1477 se refiere a esta costumbre de las siervas "que quando se ocupan en los servicios y oficios humildes, alzan y remangan las faldas de la saya porque no se les hava de ensuciar" (Bernis, $1979,11,861$.

faldetes. Se corresponde esta prenda con la denominada en castellano fa/di$1 / a$, que sólo era visible cuando se levantaban las mujeres la falda del vestido. La primera mención corresponde a 1580 «las faldetas de su mujer" (AHN, inq., leg. 550/5). Una prenda bien descrita es la que aparece en un inventario de 1585: "unes faldetes de filadis naranjat, ab una faixa de vellut carmesín (Barceló, 1984, 107). Se citan otras de paño uunas faldetas de estameña azuln (1607. AHN, Inq., leg. 935, caja 2).

faltriquera. Este bolsillo que se colgaba a la cintura aparece sólo referido a hombres. Se documenta por primera vez en 1593 y hasta 1609 , bajo las formas faltriquera y fratiquera (AHN, Inq., leg. 551/3, 551/39, libro 937 , f. 551 y libro 939 , f. 17 ).

gipó o jubón. Aunque era una prenda de vestir masculina, que se documenta ya en 1446 («un gipó d'estamenya blava». Barceló, 1980,61), aparece en 1583 entre los gastos de la tutela de dos niñas: "una alna de raxa negra... per a dos gipons" y un gipón (ARV, Clero, leg. 749/1949-50. 1591). Los había de varios tipos de tela: uun gipó de orlanda de home usat» (1585. Barceló, 1984, 107), uun xubón de lienço blanco con unas mangas postiças» (1591. AHN, Ina., leg. 555/6). A veces se utilizaba el aguatado para esconder cosas, como unos papeles que se encontraron "dentro del jubón" de un morisco cenbuelta en algodón del jubón» (1602? AHN, Inq., leg. 554/17). En una ocasión se identifica esta prenda con otro vestido exterior: "el sayo o jubón» (1600. AHN, Inq., leg. 551/39).

gregüescos. Este tipo de calzón corto y ancho era prenda de hombre. Los que llevaban los moriscos eran de paño. Se mencionan en 1602 "greguescos verdosos", "dos greguescos de paño pardo" y "greguescos de paño verden (AHN, Inq., leg. 554/18).

llançol. Vide "săbana».

mangas. Se utilizaban como accesorio de los trajes, para cubrir la camisa. Asi se citan en los inventarios, como objetos independientes: "unas mangas de terciopelo negro guarnecidas con una trença de oro» (1563. Cf. Apéndice, Cl, uunes mànegues de vellut» (1604. APN, prot. F. Sanchis), unas mangas postiçasn de un jubón (1591. AHN, Inq., leg. 555/6).

marlota. Esta conocida prenda de vestir morisca tan bien descrita para la $20-$ na granadina se ha documentado una sola vez en 1604 entre el ajuar de una morisca de la Vall d'Uixó: "una marlota de vellut guarnida ab randes de orn (APN, Prot. F. Sanchis). Fue prenda usada también por los cristianos, que en Valencia la distinguen de otras con el apelativo morischa como consta en algunos inventarios del siglo XV: "una morlota morischa de seda de diversos coloresn (Alcover, s. v.).

mocador. Sólo se menciona en uno de los inventarios consultados "dos mo- 
cadors, lo hun obrat de negre y lo altre de naranjat" (1585. Barceló, 1984,1071 . Posiblemente se trate de los velos que utilizaban las mujeres para cubrirse el rostro cuando iban de viaje (Bernis, 1962,63).

ropa. Aunque este vestido de encima, que se colocaba sobre la saya o sayo, podía ser de hombre o de mujer, sólo se encuentra mención a él en el inventario de los bienes de Victoria Filomena, rica morisca de Benissanó. Bernis afirma que era una prenda de lujo. Se mencionan dos: "una ropa de terçiopelo negro" y uuna ropa grande de tafetán girasol que la llaman loba (Cf. Bernis, 1979, II), con alas, guarneçida de terçiopelo de grana" (1563. Apéndice C).

ropilla. Era una prenda muy corta que vestían los hombres sobre el jubón y que recibia también el nombre de ropeta (Bernis, 1979, 11, 119). Sólo se menciona en relación a hombres y una de ellas llevaba cosida una bolsa "por la parte de dentro" (1602. AHN, Inq., leg. 555/21; 1602. AHN, Inq., leg. $554 / 18$ y 1602 . AHN, Inq., libro 938, f. 169).

sábana. Este es el nombre con que aparece en los inventarios del sig lo XVII lo que en épocas anteriores (siglos XIV-XVI) se menciona como "llançol», que si bien pudo designar el cuerpo de cama, hacía referencia también a un tipo de manto, generalmente de tejidos ligeros, que llevaban hombres y mujeres. Otras veces se cita esta misma prenda bajo la palabra "lienço": 1351 "dos parells de llançols" (AMV, Lletres del Rei, g3-2): 1446 "dos lançols, hú de cap per a mora e altre ab dos listes vermella e negra", "un parell de lançols de dos teles" (Barceló, 1980, 60); 1585 uun llençol nou de Ili, gran" (Barceló, 1984, 107); 1602 uun pedaço de lienço delgado que será dos varas" (AHN, Inq., leg., 554/18). También se ofrecian como presente a los alfaquíes moriscos "gallinas y lienços" (1605. AHN, Inq., leg. 551/43) sin que sea posible averiguar si se trataba de pedazos de tejido, como "un lienço para hazer colchones moriscos de colores" (1602. AHN, Inq. leg. 554/18/ o se trataba de prendas de vestir.

saboyana. Se trata de unas faldas que como prenda exterior tenían una forma parecida a las basquiñas y estaban abiertas por delante. Sólo se mencionan entre las ropas de dos ricas moriscas: la hija de $V$. Baya, de Benifairó de Valldigna y $V$. Filomena, de Benissanó. La de la niña era "una saboyana de vayeta" (ARV. Clero, leg. 749/1949-50.1591); la de la mujer, "una saboyana de paño verde guarneçida de terçiopelo, a la cristiana" (Cf. Apéndice, $\mathrm{Cl}$.

saquillo. Otro complemento que, como la bolsa, se llevaba atado al cuerpo. No se ha podido averiguar si era utilizado indistintamente por hombres $y$ mujeres. Se cita, en relación con un morisco, "un saquillo de cuero de a luda" (1603. AHN, Inq., leg. 554/7).

saquo. Sólo aparece en el inventario de un artesano mudéjar de la morería de Valencia de 1446 la mención a "un saquo vaquero" (Barceló, 1980, 60). Sobre sus formas y otros detalles cf. Alcover.

saraüell. Se trata de una prenda interior, tanto de hombre como de mujer, bien conocida. En los documentos consultados se mencionan unos "çaraguelles" que llevaba una morisca (AHN, Inq., leg. 548/3). Se colocaban directamente sobre la carne y cubrian desde la cintura a los pies. A veces 
se da el nombre de esta prenda a un vestido de fuera masculino como el calzón de negrilla, que en las huertas del Levante se sigue utilizando para cubrir los zaragüelles. Se citan en 1585 uns sarahuells negres de drap, forrats de telan (Barceló, 1984, 107) que debían usarse en dias de fiesta o solemnidades. Véase también infra § 2.b. s. v. "sarawil».

saya. Este era el traje que usaba la mayoría de mujeres de cualquier condición. Las sayas se ajustaban sobre la camisa y solían estar forradas (Bernis, 1979, 11, 1201. Las habia de camelote o de paño; entre las primeras se citan: "unes sayes de chamellot usades de carmesí ab barret de bellut» 11513 . ARV. Bailia 329, 1.631 ), "una saya de chamelote carmessi guarnecido con terciopelo negro" y otra "saya de chamelote amarillo, guarnecido con terciopelo carmessí o de granan, ambas de V. Filomena ( 1563. Apéndice, C). A esta misma morisca pertenecía una "saya de paño verde guarnecida con vellut verden. La saya también se recogía enfaldada y en sus pliegues se ocultaban objetos: una morisca escondia algo en la wenfaldadura de una saya que tenía enfaldada" (AHN, Inq., leg. 550/11). Esta prenda no debía llevarse muy ceñida, según revela el siguiente testimonio de un registro efectuado por un guardia a una morisca, pues «éste handándola tentando la halló junto a las carnes debaxo del sobaco tenía un bulto y éste metió la mano y la dicha mujer afioxó y se lo dexó caer el dicho bulto entre las piernas y baxándole éste la saya se cayó con la mesma saya en el suelo y ella se puso de pies sobre ello y mirando éste, la dicha muger se halcó la camisa diçiendo: "mira como no tengo nada" y éste alçó la saya del suelo y halló debaxo el libro.... (1585? AHN, Inq., leg. $553 / 131$. Véase infra $\$ 2 . b$, s. v. "šaya".

sayo. Es el traje masculino más común, que se vestía sobre el jubón. Aparece citado en 1446 «un sayo blau» (Barceló, 1980, 601. Como se indicó en el artículo dedicado al gipó o jubón, en ocasiones hacía las veces de éste; así un morisco escondia algo uentre la camisa y el sayo" (1602. AHN, Inq., leg. $555 / 211$. El forro de algunas de estas prendas servia también de escondrijo: "en el aforro del sayon (1581. AHN, Inq., leg. 550/25; 1608. AHN, Inq., libro 918, f. 442). Quizá por estar alguno forrado era preciso "espulgarle" (1581. AHN, Inq., leg. 550/25). La baja calidad de otro explica que pudiera romperse con un cuchillo romo (1581. AHN, Inq., leg. $554 / 17)$.

sombrero. Las descripciones de los inventarios no especifican si se trata de sombreros femeninos o masculinos. Es posible que el descrito como wun sombrero de vellut ab una randa de or v cordollares de orm 11585. Barce|ó, 1984, 107) tuviera ruedo, pero no es fácil determinar si bajo el sombrero se cubrían los cabellos con alguna toca. Los que se mencionan en procesos inquisitoriales no ofrecen ninguna particularidad y eran de hombre 11583. AHN, Inq., libro 936, f. 346; 1609. AHN, Inq., libro 939, f. 12). Véase infra § 2.b, s. v. "qūnza" ".

toca / toquilla. Esta prenda, que se usó a modo de sombrero o turbante (cf. Bernis, 1979, 11, 27-281, se menciona en 1446 entre los bienes de un hombre: "una toqua, los caps blaus", cuyas puntas serían las que quedaban colgando una vez formado el turbante (Barceló, 1980, 60). Véase además s. v. "tovalla" e infra \$2.b, s. v. «farja».

Respecto a la toquilla, no ha sido posible acertar a qué prenda se refiere Se dice en el proceso contra un morisco de Yátova que éste había alabado 
en público que un alfaquí "le havia dado una toquilla" (1608. AHN, Inq., leg. 551/37; 1609, AHN, Inq., libro 939/60).

tovalla. Era una especie de turbante que llevaban los hombres. Durante la época mudéjar, los musulmanes estaban obligados a llevar una "tovallola blava" como signo distintivo (Barceló, 1984, 85). En un inventario de 1446 se mencionan "unes tovalles chiques, de dos alnes pasades" (Barceló, 1980,60$)$. En otros textos se hace referencia a "tovalletes", "una tovallolan y uuna tovaja de redn (1585. Barceló, 1984, 107; 1602 ? AHN, Inq., leg., 554/181.

vel. Prenda de vestir o complemento de la indumentaria femenina. Sólo se cita en el inventario de los bienes de la casa de un rico mercader de la Valldigna (1585) un vel vermell, ab caps de or" y "tres vels, lo hu de tela de or; lo altre de seda naranjada y lo altre de seda blanca" (Barceló, 1984, $107)$.

zurrón. Estas grandes bolsas, que eran utilizadas por los campesinos y pastores aparecen entre los bienes de moriscos procesados por la Inquisición en dos ocasiones. De uno de ellos se dice que estaba uatado, que era de cue ro y tenía enzima un pedaço de lienço blancon (1584. AHN, Inq., libro 936, f. 379; 1603. AHN, Inq, leg. 554/7).

Entre las joyas y otros objetos de valor se han encontrado las siguientes:

albolares / erbolaris. Pendientes en forma de arete, que sólo se citan de oro. $\mathrm{Se}$ mencionan entre las alhajas de Victoria Filomena (1563. Apéndice, C) "unas arracadas albulares a la morisca de oro"; también en el ajuar de una morisca de la Vall d'Uixó se habla de cunes albolares de or" (APN, Prot. F. Sanchis, 16041. Probablemente la joya descrita en 1585 como "uns erbolaris ab sis erbolaris" (Barceló, 1984, 107) haga referencia al mismo tipo de pendientes.

anillo. Lo llevaba un morisco, pero no se especifica de qué materia estaba hecho ni cuáles eran sus características 11607. AHN, Inq., libro 938, f. 3601 .

arracades. También estos pendientes de arete, como los albolares, son siempre de oro, según los inventarios y ajuares. Se mencionan uunes aracades o campanes" (1604. APN, Prot. F. Sanchis), "unas arracadas de oro a la christiana» y unnas arracadicas de oro pequeñas a la christiana» 11563. Apéndice, Cl. Como puede apreciarse, debían existir diferencias entre esta joya morisca y su homónima cristiana. En la figura 1 pueden observarse dos ejemplares de pendientes de plata: un arete y una arracada con la mano de Fàtima en relieve en uno de sus lados.

axorca. De este brazalete sólo se mencionan dos ejemplares entre los bienes de Victoria Filomena, que se describen del siguiente modo: "dos axorcas de oro a la christiana" (1563. Apéndice, C). 
cadena. Se menciona una "cadena de oro a la christiana" (1563. Apéndi$\mathrm{ce}, \mathrm{Cl}$ cuyo fin se nos escapa por completo. Pudo destinarse como adorno de algún tocado, como collar o como cierre de alguna prenda de vestir.

capell. Esta especie de tocado se cita en 1585 como "un capell de perles" (Barceló, 1984, 107). Podría tratarse de un tipo de cinta o cordón que se colocaba sobre la toca al estilo de las tiras de cabeza (Cf. Bernis, 1979, II, 1311 .

cascaveles. Aunque no es seguro, "unos cascaveles de plata e media luna con letras arábigas» (1590. AHN, Inq., libro 937, f. 227) podrian ser unos pinjantes que colgaban de alguna tira de cabeza para adornar el tocado. Podrían tener relación asimismo con las unóminas" y "patenas".

cofia. Este tocado, con forma de casquete que se acoplaba a la cabeza femenina, figura en el ajuar de una morisca, especificándose que se trata de "una cofia de aljófar" (1604. APN, Prot. F. Sanchis). Podria relacionarse con el capell antes mencionado o los capillejos y capellos usados por las damas españolas (Cf. Bernis, 1979, II). Véase infra $\S 2 . b$., s. v. "qufyah".

collar. A tenor de las descripciones, los collares estaban formados por granos de oro de distinto grosor según los modelos. Entre los citados figuran un collar de or, ab molts grans" (1585. Barceló, 1984, 107), "un collar de or ab huit dodzenes y deu grans de or morisch, pesant huit doblesn (1604. ARV, Clero, leg. 752/1958). Se menciona también "un collar" entre las joyas del ajuar de una morisca (1604. APN, Prot. F. Sanchis). Existían otros tipos de adornos para el cuello formados por perlas y piedras, como los encontrados en poder de Ali Eça, mudéjar de Tales (Onda) en 1500, y que consistian en uun collaret de perles, de gruxa los grans com de dacsa, poch més o menys, en sis casetes; ço és, de tres fils cada caseta e cinch grans d'or e dos grans d'argent e quatre pedres de vidre blau; lo qual collaret ha pessat pes de una castellana e un ducat" y también "un altre collaret de perles menudes, com a grans de mill, ab quatre pedres d'ambre e quatre grans d'argent, ço és los dos chichs e los altres dos majors e $V$ grans de coral chiquets; lo qual pessà tot pes de tres castellanes e un florí, e .XVII. grans d“or" (Apéndice, D), Véase también infra § 2.c, s. v. "halqa" y qulyär".

manilla. Se trata de aros a modo de brazalete o pulsera. Según su tamaño, se mencionan sueltas o por grupos: "huit manilles de or" (1585. Barceló, 1984, 107); "una manilla de or morisch, pesant sis dobles y mija" (1604. ARV, Clero, leg. 752/1958); uunes manilles de plata" (1604. APN, Prot. F. Sanchis); "cinco pares de manillas de oro hechas a la christiana" (1563. Apéndice, C); "Cuatro manillas de oro" (1602. AHN, Inq.. leg. 550/11); uunas manillas de oron (1602. AHN, Inq., leg. 550/11; 1609. AHN, Inq., libro 939, f. 341.

nómina. Parece hacer referencia a ciertas plaquitas de metal precioso, también denominadas patenas, que, a modo de talismán o amule to, llevaban los moriscos. A veces los textos inquisito riales las llaman "dómina" (Labarta, 1981-2, 112 \}. Existen todavía algunos ejemplares en los museos. En 1593 se describe uno de ellos del modo siguiente: "una nómina de oro, 
con ciertas letras arábigas escritas en ella de la secta de Mahoma” (AHN, Inq., libro 937, f. 5421. Con este mismo nombre se designan también los conocidos "herces" escritos sobre papel. Véase infra § 2.c, s.v. "dûmina".

patena. Relacionado con la nómina, este tipo de medallón o dije se describe en 1590: "dos patenas de plata, en la una pintado el sol y en la otra una mano, con letras arávigasn. A estas placas se refiere una orden dada por la Junta de la Capilla Real de Granada (1526) y iuego recogida por el Sínodo de Guadix (1554) disponiendo que los moriscos "no traygan al cuello unas patenas que algunos usan traer con ciertas letras o insignias arábigas con una mano en medio o lunas ni otra cosa semejante y las que tuvieren hechas las deshagan dentro de dos meses y a los plateros mandamos no las hagan» (Gallego/Gámir, 1968, 116). La aparición de la mano de Fātima se puede poner en relación con el pendiente de la figura 1.

perlas. Además de constituir el adorno de cofias y capells, las moriscas guardaban las perlas sueltas, tal vez con destino a algún tocado, como las que poseía Victoria Filomena, que alcanzaban «tres onças de perlas» 11563 Apéndice, $\mathrm{C}$ ).

sortija. El único testimonio es el de Juan Borbay, de la Vall de Seta, que en 1616 declara ante la Inquisición que "su madre, al tiempo de la expulsión general, ... le dio a éste por despedida, en una bolsa de raso colorada, tres sortijas $y$ un poco de almiscle... (AHN, Inq., leg. 549/13).

\section{Tejidos, indumentaria y joyas atestiguados en textos árabes}

\section{a) Tejidos}<smiles>C#CC=CCC</smiles>
terćiopelo, que actualmente se usa, en especial, para fabricar alfombras. Se menciona en el Apéndice, A.

اشــــ estopa. Aparece entre los productos hilados por las aljamas de la Marina para el señor (Barceló, $1984, n .^{\circ} 26 / 3$ y 28/3. 1368 ). Ver más adelante xuca.

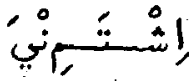

estameña. Tejido en que tanto la trama como la urdimbre son de estambre, de construcción suelta, sin dibujo e igual por las dos caras. Con esta tela estaba confeccionada la saya de una morisca $(1591$. Labarta, 1983, 82).

7 cerro. Tipo de lienzo hilado para la casa del señor por las aljamas de la Marina en el siglo XIV (Barceló, 1984, n. ${ }^{\circ} 26 / 28.1368$ ). Aparece ya en el Vocabulista.

حَرِّ 1 seda. Además de un componente del ajuar morisco que aparece a menudo en las cartas dotales, se cita como tejido de varias piezas de vestir, como almexías, tocas, cintas, alhamías y sayas. También 
en los accesorios de una casa (ucortinas») y de manera general (utelas»). Véase Vila, 1933; Barceló, 1984, n. ${ }^{\circ} 151 / 7$ (1514); Labarta, 1983 (1570-80, 1580-90, 1591); Labarta, 1982 (1587): Labarta (en prensa) (1581-83). ARV, Clero, leg. $732 / 1905$ (1558); Alc. s. v.
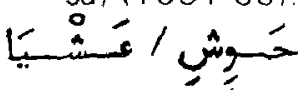

recamo, galón. Parece tratarse del galón o cinta de pasamanería que guarnece los vestidos. Alc. cita "orilla de vestidura, orilla bordada y orillo de paño = háxia havíxin. Se menciona en el documento $A$ del Apéndice dos veces $(1.7$ y 21$)$ confeccionado, al parecer, con seda. (Cf. Marçais/Guiga, II, 824-5).

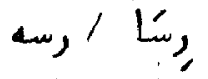

¿raso / rissa? Podría tratarse del raso, pero, aunque no esté muy bien establecida la naturaleza del tejido llamado rissa, parece que debería contemplarse también esta posibilidad (Cf. Bernis, 1979, II y Dozy, I, 495 s.v. râsa). De esta tela estaba hecho un manto (1587. Labarta, 1982) y un torcamà (Apéndice, A). Quizá haga referencia a un tipo de hilado en forma de rizo, como el conocido popularmente como "toalla", es decir, felpa o bien el terciopelo llamado de fondo rizo, normalmente de color negro.

or

ســتــ satén, setí. Según unas ordenanzas del gremio de zapateros de Valencia se utilizaba el seti para recubrir cierto tipo de zapatos. Aún hoy se emplea en el calzado de las mujeres que visten la indumentaria fallera. $>$ rus < podría referirse a un tipo de satén rasado (Sesma/Libano, 1982, 151). Se menciona en el documento B del Apéndice.

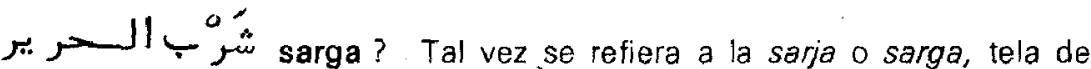
seda igual por las dos caras y sin dibujo. Se empleó en dos waqáyas con las puntas doradas (AMCoc., Pergamino s. XVI).

lienzo.

Según Alc. se designaba con esta palabra (xuca, xúqca, xoqca, xoqca) "tela", "lienço, paño de lino", "naval lienço", utela de cedaço". Parece tratarse del lienzo que se obtiene del cáñamo y que, según el proceso, daba la estopa, estopó, clavell y cerro. Cf. Labarta (en prensa) (1581-83); Barcelo, 1984, núms. 20/2, 24/1, 26/2,27/1 y $31 / 1$ (1368).

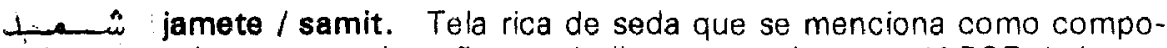
nente de una toca de paño y se indica que es de grana 11587. Labarta, 1982, fol. $3 r$.

o lana. Aparece entre los bienes que se entregan a la novia en el ajuar y normalmente ascendía a un quintal. En época morisca pudiera tratarse ya de una entrega simbólica. (AMCoc., Pergamino; Labarta, 1983. 1570-801.

ن mismo grosor, y que, como se sabe, es la forma más sencilla de tejer. Se podia usar solo o en combinación con terciopelos y telas labradas 11581 . 8.3. Labartal.

ق adúcar / alducar. Seda que da el capullo defectuoso, ocal o manchado. También recibía este nombre la tela tejida con ella (Cf. Santos, 1981, 183 y ss.). Es posible esta acepción a tenor de la 
descripción de algunos diccionarios (Cf. Dozy, s. v. qazz). Aparece en un texto de 1587 medido en onzas (Labarta, 1982, 154). En el Apéndice, A se cita una almexía con adúcar rosa y anaranjado.

lino. Textil de origen vegetal del que se obtienen tejidos de lujo como las batistas, tuleș., gasas, encajes, blondas, etc. Aparece en los ajuares de las moriscas, normalmente expresado en quintales (Vila, 1933; 1570-80 y 1580-90. Labarta, 1983; AMCoc., Pergaminol. Las mudéjares de la Marina tejían lino para la casa del señor en el siglo XIV (Barceló, 1984, núms. 15/3 y 26/2).

مـ paño. Palabra que según Corriente $11980,207 \mathrm{y}$ n. $43 ; 1979,485 \mathrm{n}$. 1) deriva del nombre de la ciudad de Amalfi. Parece utilizarse tanto en el sentido de tejido de lana muy tupida y con pelo corto, como con el más genérico de "tela». Esta última acepción se encuentra en

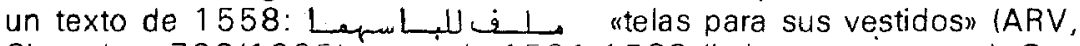
Clero, leg. 732/1905) y otro de 1581-1583 (Labarta, en prensa). Con este tejido se menciona en 1587 unna cota o túnica celeste de paño con jamete grana" (Labarta, 1982, 153 y $3 r$ ) y una saya en 1591 (Labarta, 1983, 82). El paño más tosco, de color pardo y sin tinte, recibía el nombre de "pardillo"; se atestigua en un documento de 1587: "unos zaragüelles pardillos sin trinxan (Labarta, 1982, 155 y $10 \mathrm{r}$.

\section{b) Indumentaria}

○ـ brial. Palabra tomada del catalán y que designaba el faldón que llevában las mujeres y llegaba desde la cintura hasta los pies. Equivale según Alc. (p. 119) al pollót o saya. Actualmente se llama con este nombre, en varias zonas valencianas, a las enaguas. Se documenta en 1591 (Labarta, 1983, 82). Véase supra $\$ 1$, s. v. "brial».

برغــــ alpargata. Calzado de cáñamo o esparto. Según Voc.

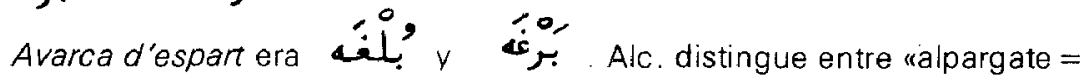
párga pargát"; "esparteña calçado deşto = párga min hálfe" (como confir-

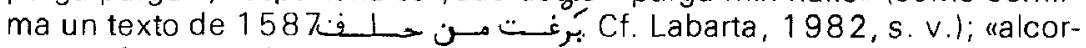
que = párga", "calçada cosa de chinelas = mulébeç alparguát", "calçada assi = parguát». En época morisca la sierra d'Espadà, en la actual provincia de Castellón, era un importante centro productor de este tipo de calzado. (Labarta, 1982; Labarta, en prensa, docs. de 1587 y 1581-83). Véase supra § 1, s. v. "alpargata».

بـ pr. En un documento de 1581-83 se menciona dos veces este galón o trencilla que guarnece y adorna las ropas (Labarta, en prensal.

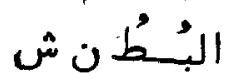

botones / botons. Se citan, sin especificar la materia de que estaban hechos, en unas cuentas de 1581-83 (Labarta, en prensa). Se trata del plural del catalán botó.

تُ

torcamà(ns). Sólo aparece en el documento $A$ del Apéndice (1.14). No se ha podido esclarecer satisfactoriamente qué cosa sea >risâ<; cf. supra § 2.a. 
vestido. Esta voz genérica se utiliza en los textos más antiguos para referirse a tela, paño o lienzo (Barceló, $1984, n{ }^{\circ} 28 / 2$. 13681. En documentación morisca parece usarse con el valor de "vestidos" (1580-90. Labarta, 1983, 86). En una ocasión se especifica que se trata de una toca (Barceló, 1984, 204: coge esta palabra bajo "mongil vestidura de monge", "vestıdura del cuerpo solo", "veste lo mismo es que vestidura", "abito".

b_ jaquet / chaqueti. Vestido exterior de hombre o mujer que cubría el torso sin llegar más abajo de la cintura. Los había con mangas o sin ellas (Labarta, en prensa, doc. de 1581-83).

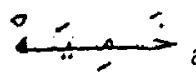

alhamia. Aunque el nombre con el que se designa esta prenda hace referencia al tejido (de algodón o percal y seda cruda, cf. Dozys. v.), no ha sido posible averiguar sus características. En un texto de 1591 se indica que es de seda (Labarta, 1983, 83).

bـ gado por unas costuras y otros artículos del oficio de alfayate, con sentido genérico (Labarta, en prensa, 6v). En otro texto, de 1583, se indica que los extremos de una alvaquaya o toca estaban bordados con hilo de oro (Labarta, 1983, 73).

J, J, Podría tratarse de la voz redi que Alc. recoge bajo la acepción "paramento, cortina o corredorn. Este sentido queda aclarado con la documentación recopilada por Martínez Ruiz 11972, 168-9 s. v. y 1976, 18 b). Sería, según estos textos, una especie de gran cortina. Con todo, la vocalización del documento de 1587, en el que aparece la palabra, puede hacer pensar en otro significado. Tal vez la forma árabe refleje el romancismo castellano red o catalán ret o reda, y parece no guardar relación con el étimo ridś propuesto por Martínez Ruiz para "redí" (1976, 18 b).

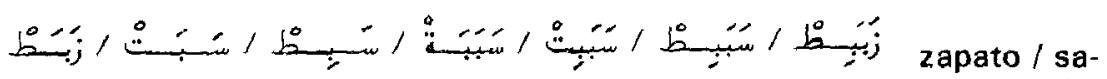

bata. Se tratá de la denominación del caizado, como io atestigua Alc. "calçado común = çapát çapápit". (Además de los ejemplos del documento $B$ del Apéndice, cf. Barceló, 1984, núms. 205 y $206 / 14$ del año 15941. Según el testimonio que aquí se publica, el zapato se confeccionaba con suela (satha, en Alc. bajo "suelo como quieran) fina. Por unas ordenanzas del gremio de zapateros de Valencia de 1513 (Piles, 1959, 151 ) quedaba prohibido obrar "çabates de dos soles que aquelles tal cabates no sien cosides menys de dos costures, ço és, la una en la jus sola e l'altra en la sobre sola, e que la jus sola sia de cuyro de bou e la sobre sola, millorant aquelles dites çabates de dos soles e la girada, sia de cordovàm. A este tipo de calzado parece que se refiere el tex to del Apéndice median te la voz catalana yuyu/at/S(a), esto es «jus-solat» o con suela interior. A tenor de las diferentes piezas de que se componía el calzado, que recoge una tabla de 1612 custodiada en el Archivo Municipal de Valencia (Piles, 1959, lámina) se advierte que las suelas se cortaban en una pieza y la "giradan era otro pedazo de cuero que se cosía a la suela dando la vuelta a ésta. La medida de la suela se contaba y cuenta mediante un cartabón dividido en "puntos". En el texto B del apéndice se señala esta medida con la voz punt, pl. abnit, atestiguada ya en Alc. como upunto que cierra la sentencias (Corriente, 1981, 15). De los diez calzados que se mencionan en 
el texto, seis son de 5 , uno de 6 y dos de 7 puntos; no se indica la medida del zapato de "la pequeña". Como reférencia, se pueden aducir unas ordenanzas de la ciudad de Logroño de 1607, donde se advierte que los zapatos de niño no llegaban más allá de los cuatro puntos, mientras que los de adulto (hombres y mujeres) sobrepasaban los cinco (Ramírez, 1981, 39). Por lo que se refiere al material, todos los que cita el texto $B$ del Apéndice son de seti ras (véase supra § 2.a, s. v. "setí»).

zaragüelles / saraüell. Esta prenda, va descrita antes (§ 1. s. v. "saraüell») aparece en una ocasión vocalizada en su forma plural que, a tenor del testimonio de Alc. («bragas = çaráguil caraguilít») podría ser la usual, por el singular, como ocurre con el castellano "zaragüelles" o "pantalones". En 1587 se citan unos "pardillos sin trinxa" o pretina (Labarta, 1982, 155).

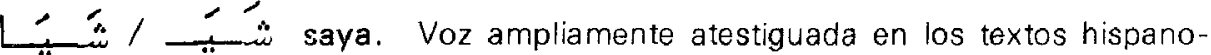
árabes (cf. Simonet s. v. xaya). Se documenta en 1591 una de color morado, de paño, y otra amarilla de estameña (Labarta, 1983, 82). Aparece además en el documento A del Apéndice (1.5). Véase supra § 1, s. v. "saya".

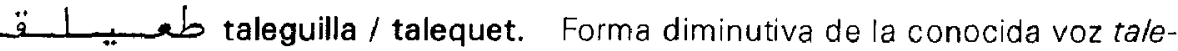
ga, para referirse a un saquito o bolsita en la que llevar dinero o cosas menudas. En el documento de 1587 donde aparece, se indica que es "celeste" (>samiyâ<) (Labarta, 1982, 155).

$\ddot{0} \ddot{0}$ : cuello. Los textos en que aparece esta voz señalan que son de seda (Cf. Apéndice, A, 1.22; AMCoc.; Barceló, 1984, n. $151 / 71$. Evidentemente se trata de un cuello postizo para las camisas o alcandoras, como recoge Alc. s. v. "collar de vestido" y "cabeçón de camisa = táuq".

فر toca. Atuendo femenino para la cabeza. Según Alc. "farka = toca sagrada de monja", sin que se pueda averiguar por el momento en qué se distinguía de las usadas por las mujeres laicas. Se menciona una en 1591 (Labarta, 1983, 82). Véase supra § 1, s. v. "toca".

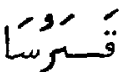
documentado en otras fuentes hispanoárabes, aparece en un texto de 1587 (Labarta, 1982, 11r).

b cota. Traje exterior tanto masculino como femenino que cubría desde el cuello hasta cerca de los pies. Alc . atestigua "mongil=cóta" y "cota de malla = cóta min zarád". En un documento de 1587 se menciona una "cota azul pastel de paño con jamete grana" (Labarta, 1982, 3r). Véase también supra $\S 1$, s. v. "cota".

Xb. - relación con la faja que tiene actualmente. Se documenta en un texto de 1587 (Labarta, 1982, 11r).

苑 cofia o capell. (Labarta, 1983,82 y cf. supra $\S 1$ 1, s. v. "capell" $y$ ucofia"). 
رُ alcandora. Prenda conocida y ampliamente documentada. Se menciona en un texto de 1581-83 (Labarta, en prensa) y en el Apéndice, A. donde se especifica que es de hombre.

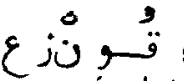
más detalles sobre el material de que estaba hecho ni sobre su forma barta, en prensa). Véase también supra § 1, s. v. "sombrero".

L. Sapa. Se menciona en un texto de 1587 , señalándose además que es azul pastel y vieja (Labarta, 1982, 151). Véase supra \$ 1, s. v. "capa".

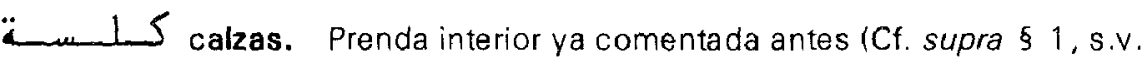
"calzas"). Se documenta en un texto de 1587 (Labarta, 1982, 151 ).

C

alquinal. Tocado femenino al que se ha aludido ya (véase supra $\$ 1$, s.v. "alquina|»). El documento árabe de 1591 en que se menciona una prenda de este tipo añade que es morado y bordado con oro (Labarta, 1983,821 .

vestidura o vestido. Término genérico, que Alc. recoge bajo los epigrafes: "abito vestido", "vestidura generalmente", "vestidura enforrada", "vestidura del cuerpo solon, "vestidura real", "vestido qualquiera", "trage de vestido", dando para ellos el equivalente árabe libic. En un documento de 1558 se menciona el paño (malf) para su confección (ARV, Clero, leg. 732/1905; Vila, 1933).

: volvian las moriscas. Documentada en un texto de 1591 (Labarta, 1983, 82).

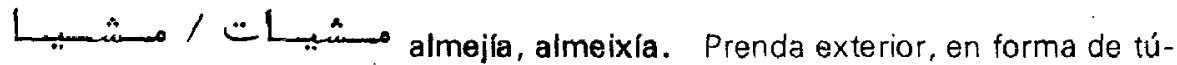
nica con mangas. Podía ser de paño o de seda, e iba adornada en las orillas con labores de colores diversos. Se posee documentación sobre ella desde el siglo XIII (Roca, 1952, doc. 17, págs. 198-199 "ll almeixes de li planesn). Véase Apéndice, A, líneas 6, 7, 8, 9, 11; y ARV, Clero, leg. $732 / 1905$.

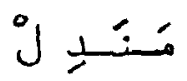

Alc. da la equivalencia "tovajas = mandil manidilm. Podria tratarse de una prenda de vestir (cf. $\S 1, s . v$. "tovalla»), pero también de un accesorin doméstico

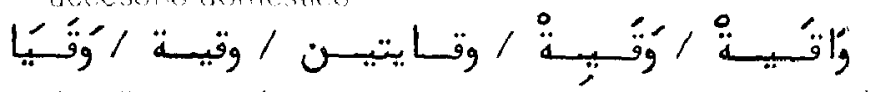

alvacaia, toca.

Ampliamente documentada; se trata, en la mayor parte de los ejemplos recogidos, de una prenda de lujo, confeccionada en seda de color y adornada en sus extremos con bordados de oro lLabarta, 1983,64,69, 70, 81; AMCoc.; Apéndice, A, línea 201.

c) Joyas

جـ jacerino / jaseran (variante antigua gisaram). Pieza de orfebrería hechá de malla. El documento en que se cita, de 1587, menciona además que es "de plata" (Lábarta, 1982, 150). 
ه aljofar. Perlas. Hay abundantes menciones a ellas, ya sean sueitas, ya incorporadas a adornos de cabeza (AMCoc.; Vila, 1933; Labarta, 1983, 64 y 81 -documentos de 1570-80 y 1591-).

ح حـ collar. Alc. recoge este término bajo «armellan y «argolla», dando como equivalente árabe hilca, pl. hiláq. Parece tratarse de un tipo de collar. En un texto de 151.8 se dice que es "de torneses" (Barceló, 1984. n. ${ }^{\circ} 157 / 8,14$ l y se da su equivalente romance "collar". Véase supra $\$ 1$, s. v. "collar".

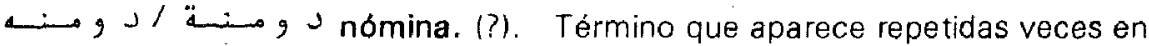
un documento de 1514 aludiendo a un objeto "de plata" tomado en prenda a la par que otros enseres de valor (Barceló, 1984, n. ${ }^{\circ} 151$ 16, 8, 15 , 17, 19). Podría interpretarse como "nómina» (Cf. supra § 1, s. v. unóminanl, especialmente si se tiene en cuenta la frecuencia de las confusiones entre fonemas con y sin nasalización.

هـ $j$ oro. Metal precioso utilizado para determinadas joyas, no especificadas (Vila, 1933; Labarta, 1983, 64 y 87 -documentos de 1570-80 y $1580-90-1$ y como hilo para bordar los extremos de vestidos y complementos

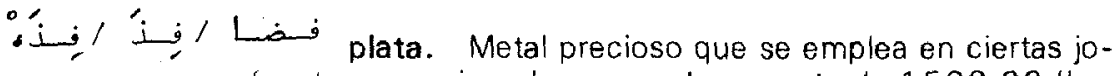
yas, no especificadas, mencionadas en un documento de 1580-90 ( $\mathrm{La}$ barta, 1983, 871. En el Apéndice, A se citan una cuchara y una nómina de este metal, del que también es el "jacerino" al que ya se ha hecho referencia.

"Collar". 
1 2 3 4 5 6 7 8 9 10 11

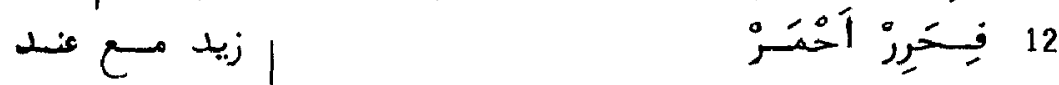
13

14 حلد زيسـ 15 16 17 18 19 20 21 22 23 24

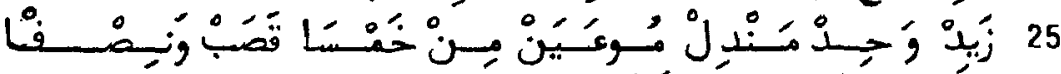
26 


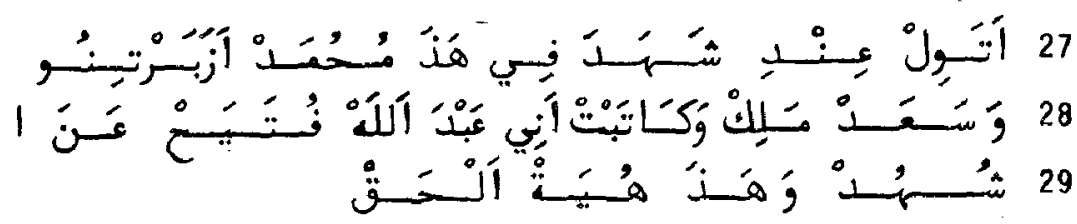

s.I. [¿1559?] ARV. Signatura provisional: Varia caja 90.

1. Yo, el siervo de Dios ${ }^{c}$ Abd Allāh Futayah reconozco

2. que mi cuñado $S a^{c} a d$ Sulaymān, de Picassent

3. trajo este ajuar que está en este albarán y se encuentra en mi poder, de

4. Ios bienes de Alamín que había llevado la hija de mi tío Alamín. Esta es la verdad.

5. Tengo en mi poder una saya de grana, con tripa de seda negra.

6. Item. Una almejía de seda, con amarillo y verde.

7. Item. Una almejía de seda, con recamos morados y anaranjados.

8. Item. Una almejía de tela, margomada con ađúcar rosa y anaranjado.

9. Item. Una almejía de tela, margomada con seda roja en las bocamangas

10. y el faldar.

11 Item. Una almejía de tela, margomada - el faldar y las bocamangas-

12. con seda roja. Item. Tengo en mi poder

13.

14. Item. Tres colchones pequeños con cintas de plata.

15. Item. una

16. Item. Un torcamà con rissa (?) nómina de

17. Item. Un par de cojines blancos, con plata cordones blancos.

18. Item. Un cojín, acordonado de grana.

19. Item. Un par de cojines de seda amarilla.

20. Item. Una alvacaia rojita, con un poquito de oro. 
21. Item. Un pedazo de recamo de seda amarilla, verde y roja.

22. Item. Un cuello de seda, de alcandora de hombre.

23. Item. Tres mandiles ...? ...

24. Item. Un par de mandiles escaqueados, cada uno de dos alnas y media.

25. Item. Un mandil escaquedado, de cinco alnas y media.

26. Escribí yo, 'Abd Allāh Futayaḥ, de mi puño y letra, conforme está

27. en mi poder este ajuar. Dieron testimonio de esto Muhumad el Zabartino

28. y Sacad Malik. Escribi yo, 'Abd Allāh Futayah, por tos

29. testigos. Esta es la verdad.

\section{APÉNDICE}

B

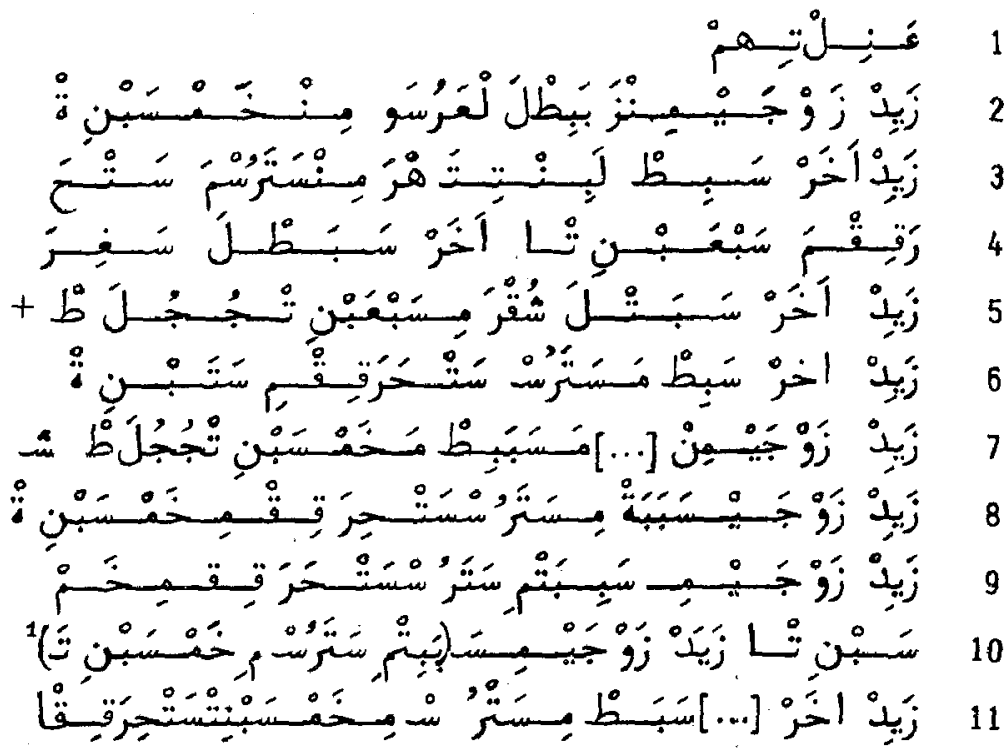

(1) El texto entre paréntesis está escrito debajo de la linea, como enmienda a un fragmento tachado en el que decía:

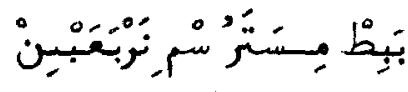


Documento incluido en el proceso inquisitorial contra Pedro Mangay (el viejo) capatero, vecino de Xàtiva.

Archivo de la Universidad de Valencia, s.]. [\{1573?]. Signatura provisional: s. XVI, caja $10.30 \times 21 \mathrm{~cm}$.

1. Memorial

2. Item. Dos pares de zapatos para la novia, de cinco punts.

3. Item. Otros zapatos para la hija de Tahra (?), de setí ras, de suela

4. fina, de siete punts. Otros zapatos para la pequeña.

5. Item. Otros zapatos para la suegra, de siete punts, jus-solats.

6. Item. Otros zapatos, de seti ras, de suela fina, de seis punts.

7. Item. Dos pares de (...) zapatos, de cinco punts, jus-solats.

8. Item. Dos pares de zapatos, de setíras, de suela fina, de cinco punts.

9. Item. Dos pares de zapatos, de setíras, de suela fina, de cin-

10. co punts. Item. Dos pares de (1) zapatos de set' ras, de cinco punts.

11. Item. Otros zapatos de setí ras, de cinco punts, de suela fina.

(1) A continuación, tachado: "zapatos de seti ras, de cuatro punts».

\section{APÉNDICE}

C

1567. Benissanó

Relación de bienes de Victoria Filomena.

AHN, Inquisición, legajo 551/13.

"E luego el dicho Señor Inquisidor le mandó a la dicha Victoria que so cargo del dicho juramen to diga qué bienes o joyas y dineros tiene y dónde.

Dixo que en el lugar de Benizanó, en casa del dicho don Ferrando de Benamir tiene los bienes, joyas de oro, dineros y ajófar siguientes:

Primo en una caxica chica que está encima de una caxa grande, en la quál caxica åy lo siguiente 
Primo cinco pares de manillas de oro hechas a la christiana Item unas arracadas de oro a la christiana

Item una cadena de oro a la christiana

Item tres onças de perlas

Item unas arracadicas de oro pequeñas a la christiana

Item unas otras arracadas albulares a la morisca de oro

Item dos axorcas de oro a la christiana todo lo qual está dentro en la dicha caxica

$60 \mathrm{~s}$.

$9 \mathrm{~s}$.

$60 \mathrm{~s}$.

$24 \mathrm{~s}$.

$3 \mathrm{~s}$.

$9 \mathrm{~s}$.

$12 s$

Item en la otra caxa mayor está lo siguiente:

Item una saboyana de paño verde guarneçida de terçiopelo a la Christiana fecha

Item una basquiña a la christiana de tafetán girasol de grana y amarillo con guarnición de terciopelo negro

Item una saya de chamelote carmessi guarneçido con terçiopelo negro

Item otra saya de chamelote amarillo guarneçido con terçiopelo carmessi o de grana

Item otra saya de paño verde guarnecida con vellut verde

Item un cuerpo de rasso de carmessi con sus mangas

Item unas mangas de terciopelo negro guarnecidas con una trença de oro

Item una ropa de terçiopelo negro

Item una ropa grande de tafetán girasol que la llaman loba con alas guarneçida de terçiopelo de grana

$6 \mathrm{~s}$

$5 \mathrm{~s}$

$7 \mathrm{~s}$

$7 \mathrm{~s}$

$5 \mathrm{~s}$.

$3 \mathrm{~s}$.

2 s. $10 d$.

$35 \mathrm{~s}$

$5 \mathrm{~s}$.

Item digo y manifiesto que tiene en la dicha arquilla arriba dicha en dineros diez coronas que hovo de una bala de lienço de don Ferrando de Benamir que vendió la dicha confessante que le ha de dar cuenta dello y que otros bienes no tiene (...)r.

\section{APÉNDICE}

D

\section{Diciembre 30. Onda}

Relación de bienes encontrados en una bolsa de Ali Eça, acusado de robar gallinas.

ARV, Bailia 1325, folio $72 \mathrm{~V}$.

"Foren atrobades per lo magnifich En Bernat Periz, batle real de la vila d'Onda, en la bossa del cint d'Ali Eça, moro de Tales, pres e detengut en la presó comuna de la dita vila, a requesta de Jaume Soriano, llaurador, per certes gallines que li havia furtades del corral que te prop lo molí de Bernat Pinòs, per stojoll fet en la persona de aquell, les cosses següents:

Primo. Un collaret de peries, de gruxa los grans com de dacsa, poch més o menys, en sis casetes; co és, de tres fils cada caseta, e cinch grans d'or e dos grans d'argent e quatre pedres de vidre blau. Lo qual collaret ha pessat pes de una castellana e un ducat. 
Item. Un altre collaret de perles, menudes com a grans de mill, ab quatre pedres d'ambre e quatre grans d'argent; co és, los dos chichs e los altres dos majors, e.v. grans de coral chiquets. Lo qual pessà tot pes de tres castellanes e un florí e xvii. grans d'or.

Item. Una nòmina morischa, cuberta de drap vermell.

Item. Un libret morisch.

Item. Unes tisores

Item. Un raor; quatre nòmines ab caractes e cifres morisques." 
INOUMENTARIA MORISCA VALENCIANA... / Barcelo y Labarta

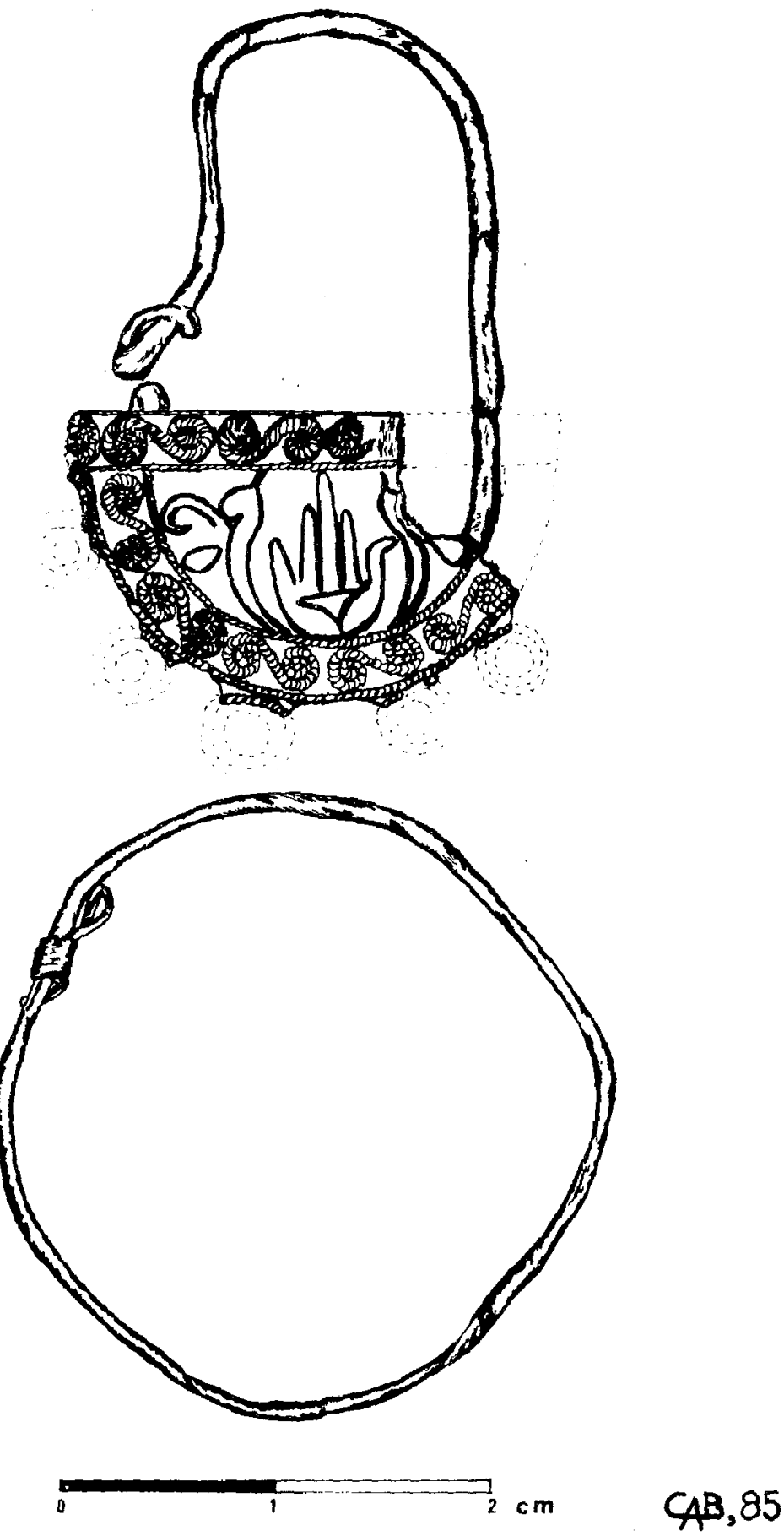

Arracada y arete moriscos de plata. conservados en el Museo Municipal de Borriana (Oibujo C. A. B.) 


\section{BIBLIOGRAFIA Y SIGLAS}

(Alc.) Pedro de AlCalÁ, De lingua arabica libri duo led. P. Lagarde), Göttingen, 1883 (reimpr. Osnabrück, 1971 ).

AlCOVER, A. M., y MOLL, F. de B. (1959), Diccionari català-valencià-balear, Palma de Mallorca.

BARCELó, C. (1980), "La morería de Valencia en el reinado de Juan Il», Saitabi, $30,47-71$

- (1984), Minorlas islámicas en el país valenciano. Historia y dialecto, Valencia-Madrid.

BERNIS, C. (1959), "Modas moriscas en la sociedad cristiana española del siglo XV y principios del siglo XV/m, BRAH, 144, 199-228.

- (1962), Indumentaria española en tiempos de Carlos V, Madrid.

- 1978), Trajes y modas en la España de los Reves Católlcos. I. Las mujeres, Madrid.

- (1979). Trajes y modas en la España de los Reyes Católicos. II. Los hombres, Madrid.

BORONAT, P. 11901$)$, Los moriscos españoles y su expulsión, Valencia. 2 vols.

CORRIENTE, F. (ed.), et al. (1979), Al-Muqtabas (V) de lbn Hayyân, Madrid.

- (1980), "Notas de lexicología hispanoárabe 11 y II)", Vox Romanica, 39, 183-210.

- (1981), "Notas de lexicología hispanoárabe (III y IV)", Awrâq, 4, 5-30.

DOZY, R., Supplément aux dictionnaires arabes, Leiden, París, 1927 (reimpresión, 1967 ).

Gallego, A., y GAMIR, A. (1968), Los moriscos del reino de Granada según el sinodo de Guadix de 1554, Granada.

GARCIA MERCADAL (1959), Viajes de extranjeros por España y Portugal, Madrid.

Gual Camarena, M. (1952-53), "Concordia entre los gremios de zapateros $V$ chapineros de Valencia (1486) Saitabi, 9, 133-144. 
LABARTA, A. (1981-2), "Notas sobre algunos traductores de árabe en la Inquisición valenciana (1565-1609)", RIEl, 21, 101-133.

- (1982), "Cuentas del tendero morisco Gerónimo Hoix (Gandía, 1587)", a/Oantara, 3, 135-171.

- (1983), "Contratos matrimoniales entre moriscos valencianos", al-Qantara $4,57-87$.

- (en prensa), "Contabilidad del morisco valenciano Josep Malux en los años $1581-1583 \%, R / E I$.

MARÇAIS, W., y GUIGA, A. (1958), Textes arabes de Takrouna, París.

MARTinez Ruiz, J. (1967), "La indumentaria de los moriscos según Pérez de Hita y los documentos de la Alhambran, Cuadernos de la Alhambra, 3, 55124.

- (1972), Inventarios de bienes moriscos del reino de Granada (siglo XVI). Lingüistica y civilización, Madrid.

PILES Ros, L. 11959), Estudio sobre el gremio de zapateros, Valencia.

Ramírez Martinez, J. M. [ed.] (1981), Las ordenanzas de la ciudad de Logroño. Año 1607, Logroño.

Roca Traver, F. (1952), "Un siglo de vida mudéjar en la Valencia medieval (1238-1338)", EEMCA, 5, $115-208$.

SANTOS ISERN, V. M. (1981), Cara y cruz de la sederia valenciana (siglos XVIII$X(X)$, Valencia.

SESMA, J. A. y LíBANO, A. (1982), Léxico del comercio medieval en Aragón (siglo XV), Zaragoza.

SIMONET, F. J. (1982=1888), Glosario de voces ibéricas y latinas, Madrid, 2 volúmenes.

TRAMOYERES, L. (1889), Instituciones gremiales, su origen y arganización en Valencia, Valencia.

VILA, S. (1933), "Un contrato de matrimonio entre musulmanes del siglo XVI", AHDE, $10,186-196+3$.

VOCABULISTA IN ARABICO, (ed. C. Schiaparelli). Florencia, 1871. 